\title{
SCALE Modeling of Selected Neutronics Test Problems within the OECD UAM LWR's Benchmark
}

\author{
Luigi Mercatali, ${ }^{1}$ Kostadin Ivanov, ${ }^{2}$ and Victor Hugo Sanchez ${ }^{1}$ \\ ${ }^{1}$ Karlsruhe Institute of Technology (KIT), Campus Nord, Hermann-von-Helmholtz-Platz 1, 76344 Eggenstein-Leopoldshafen, Germany \\ ${ }^{2}$ The Pennsylvania State University (PSU), 206 Reber Building, University Park, PA 16803, USA
}

Correspondence should be addressed to Luigi Mercatali; luigi.mercatali@kit.edu

Received 20 July 2012; Accepted 20 December 2012

Academic Editor: Oscar Cabellos

Copyright (c) 2013 Luigi Mercatali et al. This is an open access article distributed under the Creative Commons Attribution License, which permits unrestricted use, distribution, and reproduction in any medium, provided the original work is properly cited.

The OECD UAM Benchmark was launched in 2005 with the objective of determining the uncertainty in the simulation of Light Water Reactors (LWRs) system calculations at all the stages of the coupled reactor physics-thermal hydraulics modeling. Within the framework of the "Neutronics Phase" of the Benchmark the solutions of some selected test cases at the cell physics and lattice physics levels are presented. The SCALE 6.1 code package has been used for the neutronics modeling of the selected exercises. Sensitivity and Uncertainty analysis (S/U) based on the generalized perturbation theory has been performed in order to assess the uncertaintyof the computation of some selected reactor integral parameters due to the uncertainty in the basic nuclear data. As a general trend, it has been found that the main sources of uncertainty are the ${ }^{238} \mathrm{U}(\mathrm{n}, \gamma)$ and the ${ }^{239} \mathrm{Pu}$ nubar for the UOX- and the MOX-fuelled test cases, respectively. Moreover, the reference solutions for the test cases obtained using Monte Carlo methodologies together with a comparison between deterministic and stochastic solutions are presented.

\section{Introduction}

In recent years there has been an increasing demand from nuclear research, industry, safety, and regulation bodies for best estimate predictions of Light Water Reactors (LWRs) performances to be provided with their confidence bounds. In addition to the establishment of LWRs best-estimate calculations for design and safety analysis, understanding uncertainties of evaluated reactor parameters is important for introducing appropriate design margins and deciding where additional efforts should be undertaken to reduce those uncertainties. In order to address those issues, an in-depth discussion on "Uncertainty Analysis in Modeling" started to take place in 2005 within the OECD/NEA Nuclear Science Committee, which led to the creation of a dedicated Expert Group and to the launching of a Benchmark exercise, the OECD UAM (Uncertainty Analysis in Modeling) LWR Benchmark [1]. The proposed technical approach is to establish a benchmark for uncertainty analysis in bestestimate modeling and coupled multiphysics and multiscale LWR analysis, using as bases a series of well-defined problems with complete sets of input specifications and reference experimental data. The objective is to determine the uncertainty in LWR system calculations at all stages of coupled reactor physics/thermal hydraulics calculation. The UAM benchmark has been conceived to be structured in three different phases, being Phase I the "Neutronics Phase," Phase II the "Core Phase," and Phase III the "System Phase." Additionally, each benchmark phase is subdivided in a number of different Exercises in order to propagate the full chain of uncertainty in the modeling across different scales (multi-scale) and physics phenomena (multi-physics). The present paper is devoted to the solutions of some selected test problems within the Exercises I-1 and I-2 of Phase I. The Exercise I-1 is entitled "Cell Physics" and is focused on derivation of the multigroup microscopic cross-section libraries. Its objective is to address the uncertainties due to the basic nuclear data as well as the impact of processing the nuclear and covariance data, selection of multi-group structure, and self-shielding treatment. Within Exercise I1 the uncertainties in the evaluated Nuclear Data Libraries (NDLs) are propagated into multigroup microscopic crosssections. In Exercise I-2 multi-group cross-section uncertainties are input uncertainties which are then propagated 


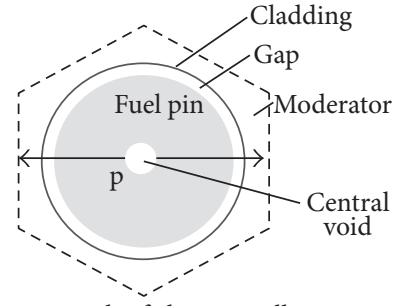

p-pitch of the unit cell

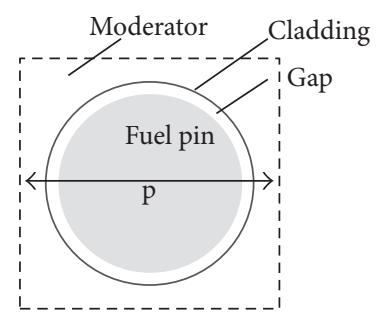

p-pitch of the unit cell

Figure 1: Types of geometries for the fuel pin-cell test cases within Exercise I-1.

through the lattice physics calculations to few-group crosssection uncertainties.

\section{Description of the Test Cases}

Within the framework of Exercise I-1 different fuel pin-cell test problems have been defined representing both square and triangular pitches. The two types of basic geometries for the unit cells are schematized in Figure 1. ered.

In this paper the following test cases have been consid-

(a) Two-dimensional fuel pin-cell problems representative of Boiling Water Reactor (BWR) Peach Bottom 2 (PB-2) [2], Pressurized Water Reactor (PWR) Three Mile Island 1 (TMI-1) [3], and Koyloduz-6 VVER1000 [4]. Each pin-cell model has to be analyzed at Hot Full Power conditions (HFP) as well as at Hot Zero Power conditions (HZP). To enhance the differences between the three cases (PWR, BWR, and VVER) the HFP case of the BWR is defined to be calculated at $40 \%$ void fraction (with a corresponding moderator density $(\rho)$ of $\left.460.72 \mathrm{~kg} / \mathrm{m}^{3}\right)$ instead of $0 \%$. Hence the PWR and BWR cases are for square pitch but with different spectra, while the VVER case is for triangular pitch.

(b) Fuel pin-cell test problems from the KRITZ-2 LEU critical experiments [5].

(c) PWR MOX (MOX 9.8\% Pu) pin-cell case representative of Generation 3 PWR designs, which in the following text of this paper will be referred to as GENIII [6].

Within Exercise I-2, different stand-alone neutronics single Fuel Assembly (FA) and minicore test problems have been proposed. In this paper we will present the solutions for the following test cases.

(a) BWR PB-2 assembly model [2]: the assembly "type 2" of the initial loading of the Peach Bottom 2 nuclear power plant is chosen for this exercise.

(b) PWR TMI-1 assembly model [3].

(c) GEN-III assembly models [6]: one MOX and three UOX FAs types with different ${ }^{235} \mathrm{U}$ enrichment and Gd content are available for this exercise.

The parameter specifications as well as the operating conditions for all the test cases analyzed in the present paper are summarized in Table 1 . The six types of FAs considered in our analysis are shown in Figure 2.

\section{Theoretical Approach and Computational Method}

The basic problem of the neutronics is the solution of the integral-differential Boltzmann equation for the neutron transport, which is a linear equation requiring the treatment of seven independent variables: three in space, two in angle, one in energy of the incident neutrons, and time. As a consequence of such a complexity, one has to keep in mind that even if the accuracy in the predictions of the modern transport codes (both Monte Carlo and deterministic) is continuously improving, there will be always approximations introduced in the calculational procedure. Examples of uncertainties are the ones originated from the basic nuclear reaction data, from the geometrical description of the problem, and from the material compositions. The knowledge of the approximations used in the analysis and of the overall calculational uncertainties is therefore essential to gain confidence in the results obtained, and sensitivity analysis and uncertainty evaluation $(\mathrm{S} / \mathrm{U})$ are the main instruments for dealing with the sometimes scarce knowledge of the input parameters used in the simulation tools [8]. For sensitivity analysis, sensitivity coefficients are the key quantities that have to be evaluated. They are determined and assembled, using different methodologies, in a way that when multiplied by the variation of the corresponding input parameter, they will quantify the impact on the targeted quantities whose sensitivity is referred to. There are two main methodologies developed for sensitivity and uncertainty analysis. One is the forward (direct) calculation method based either on the numerical differentiation or on a stochastic method, and the other is the adjoint method based on the perturbation theory [9]. In general, the forward approach is preferable when there are few input parameters that can vary and many output parameters of interest. The contrary is true for the adjoint methodology, which is the one mainly adopted in rector physics, as the source of uncertainty is mainly related to the neutron cross-sections that can represent a very notable number of variables (up to several hundred thousand). Moreover, the linear property of the Boltzmann equation makes the adjoint approach even more attractive. Since all the analysis for the benchmark cases presented in this paper has been carried out using perturbation methodologies, let us briefly recall the theoretical background of these techniques.

From a general point of view one can represent a generic integral reactor parameter $Q$ (i.e., the $k_{\text {eff }}$, a reactivity coefficient, a reaction rate, etc.) as a function of cross-sections:

$$
Q=f\left(\sigma_{1}, \sigma_{2}, \ldots, \sigma_{J}\right)
$$

where $\sigma_{1}, \sigma_{2}, \ldots, \sigma_{J}$ represent cross sections by isotope, type of reaction, and energy range (or energy group in a multigroup representation). 
TABle 1: Pin-cell data for the test cases of Exercises I-1 and Exercise I-2.

\begin{tabular}{|c|c|c|c|c|c|}
\hline Parameter & BWR & PWR & VVER & KRITZ-2:1 & GEN-III \\
\hline FA geometry & $7 \times 7$ & $15 \times 15$ & - & - & $17 \times 17$ \\
\hline FA pitch $(\mathrm{mm})$ & 152.4 & 218.11 & - & - & 216.1 \\
\hline Fuel rods per assembly & 49 & 208 & - & - & 265 \\
\hline Number of guide tubes per FA & - & 16 & - & - & 24 \\
\hline Number of instrumentation tubes per FA & - & 1 & - & - & - \\
\hline Number of Gd pins per FA & - & 4 & - & - & - \\
\hline Guide tube outside diameter $(\mathrm{mm})$ & - & 13.462 & - & - & 12.07 \\
\hline Guide tube inside diameter $(\mathrm{mm})$ & - & 12.649 & - & - & 11.27 \\
\hline Instrumentation tube outside diameter $(\mathrm{mm})$ & - & 12.522 & - & - & - \\
\hline Instrumentation tube inside diameter $(\mathrm{mm})$ & - & 11.201 & - & - & - \\
\hline Unit cell (mm) & 18.75 & 14.427 & 12.75 & 14.85 & 12.62 \\
\hline Fuel pellet diameter (mm) & 12.1158 & 9.391 & 7.56 & 10.58 & 8.253 \\
\hline Fuel pellet material & $\mathrm{UO}_{2}$ & $\mathrm{UO}_{2}$ & $\mathrm{UO}_{2}$ & $\mathrm{UO}_{2}$ & MOX \\
\hline Fuel density $\left(\mathrm{g} / \mathrm{cm}^{3}\right)$ & 10.42 & 10.283 & 10.4 & - & - \\
\hline Fuel enrichment (w/o) & 2.93 & 4.85 & 3.3 & 1.86 & $9.8(\mathrm{Pu})$ \\
\hline Central void diameter $(\mathrm{mm})$ & - & - & 1.4 & - & - \\
\hline Central void material & - & - & Dry air & - & - \\
\hline Cladding outside diameter $(\mathrm{mm})$ & 14.3002 & 10.928 & 9.1 & 12.25 & 9.487 \\
\hline Cladding thickness (mm) & 0.9398 & 0.673 & 0.69 & 0.74 & 0.578 \\
\hline Cladding material & Zircaloy-2 & Zircaloy-4 & $\mathrm{Zr}+1 \% \mathrm{Nb}$ & Zircaloy-2 & Zircaloy-4 \\
\hline Cladding density $\left(\mathrm{g} / \mathrm{cm}^{3}\right)$ & 6.55 & 6.55 & - & - & - \\
\hline Gap material & $\mathrm{He}$ & $\mathrm{He}$ & $\mathrm{He}$ & $\mathrm{He}$ & $\mathrm{He}$ \\
\hline Moderator material & $\mathrm{H}_{2} \mathrm{O}$ & $\mathrm{H}_{2} \mathrm{O}$ & $\mathrm{H}_{2} \mathrm{O}$ & $\mathrm{H}_{2} \mathrm{O}$ & $\mathrm{H}_{2} \mathrm{O}$ \\
\hline \multicolumn{6}{|l|}{ Fuel temperature $(\mathrm{K})$} \\
\hline HZP & 552.833 & 551 & 552.15 & 292.7 & - \\
\hline HFP & 900 & 900 & 900 & 521.5 & 900 \\
\hline \multicolumn{6}{|l|}{ Cladding temperature $(\mathrm{K})$} \\
\hline HZP & 552.833 & 551 & 552.15 & - & - \\
\hline HFP & 600 & 600 & 600 & - & 610 \\
\hline \multicolumn{6}{|l|}{ Moderator temperature $(\mathrm{K})$} \\
\hline HZP & 552.833 & 551 & 552.15 & - & - \\
\hline HFP & 557 & 562 & 560 & - & 584 \\
\hline \multicolumn{6}{|l|}{ Moderator density $\left(\mathrm{kg} / \mathrm{m}^{3}\right)$} \\
\hline HZP & 753.978 & 766 & 767 & - & - \\
\hline HFP & 460.72 & 748.4 & 752.5 & - & - \\
\hline
\end{tabular}

The variation of $Q$ due to variations of cross-sections $\sigma$ can be expressed using perturbation theories to evaluate the sensitivity coefficients $S$ as follows [8-12]:

$$
\frac{\delta Q}{Q}=\sum_{j} S_{j} \frac{\delta \sigma_{j}}{\sigma_{j}},
$$

where the sensitivity coefficients are formally given by

$$
S_{j}=\frac{\partial Q}{\partial \sigma_{j}} \cdot \frac{\sigma_{j}}{Q} .
$$

For practical purposes, one can consider the sensitivity coefficient as divided into two components as follows:

$$
\frac{\delta Q}{Q}=\sum_{j} S_{j} \frac{\delta \sigma_{j}}{\sigma_{j}}+\left(\frac{\partial Q}{\partial \sigma^{e}} \cdot \frac{\sigma^{e}}{Q}\right) \cdot \frac{\delta \sigma^{e}}{\sigma^{e}}=I+D,
$$

where the terms $I$ and $D$ are generally referred to as "indirect" and "direct" effect, respectively. The $D$ term in (4) reflects the hypothesis of a direct dependence of the parameter $Q$ on only the energy dependent detector cross-section $\sigma^{e}$. The $I$ term in (4) is the response perturbation due to flux perturbations. The indirect term of (4) consists also of two components, namely, the explicit and implicit ones [13]. The explicit component of the indirect effect comes from the flux perturbation caused by perturbing any multi-group crosssection appearing explicitly in the transport equation. The implicit component of the indirect effect is associated with self-shielding perturbations; in other words perturbing the cross section of one nuclide may change the self-shielded cross section of another nuclide, which causes additional flux perturbations. As an example if one considers the hydrogen, perturbing the $\mathrm{H}$ elastic value has an explicit effect because 


\begin{tabular}{|c|c|c|c|c|c|c|}
\hline 4 & 3 & 3 & 2 & 2 & 2 & 3 \\
\hline 3 & 2 & 1 & 1 & 1 & 1 & 2 \\
\hline 3 & 1 & $5 \mathrm{~A}$ & 1 & 1 & $5 \mathrm{~A}$ & 1 \\
\hline 2 & 1 & 1 & 1 & 1 & 1 & 1 \\
\hline 2 & 1 & 1 & 1 & $6 \mathrm{~B}$ & 1 & 1 \\
\hline 2 & 1 & $5 \mathrm{~A}$ & 1 & 1 & 1 & 2 \\
\hline 3 & 2 & 1 & 1 & 1 & 2 & 2 \\
\hline
\end{tabular}

(a)

Q P O N M L K J I H G F E D C B A

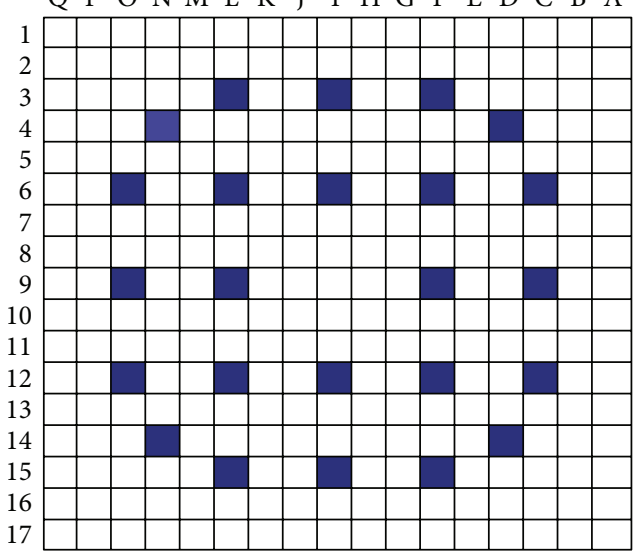

$\square$ Guide tube

$\square$ Fuel pin

(c)

Q P O N M L K J I H G F E D C B A
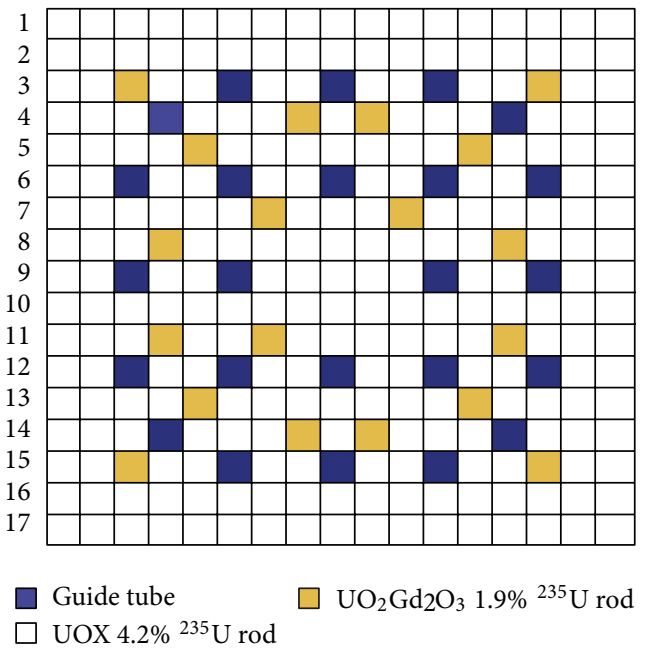

(e)

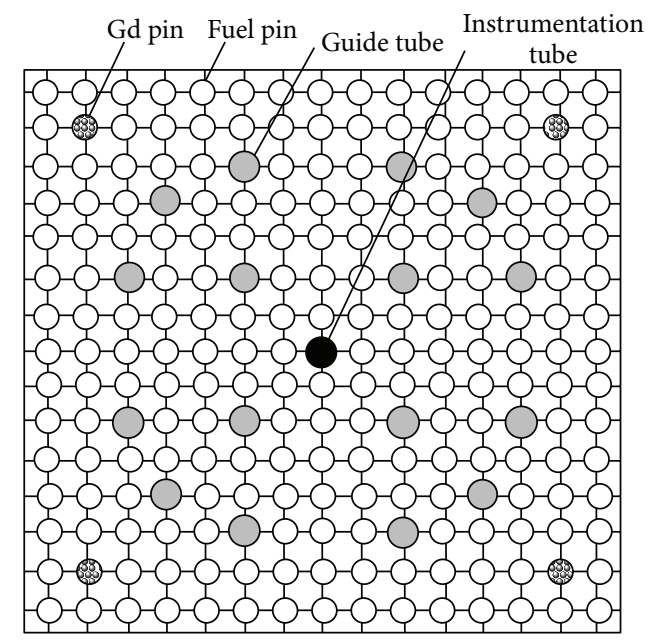

(b)

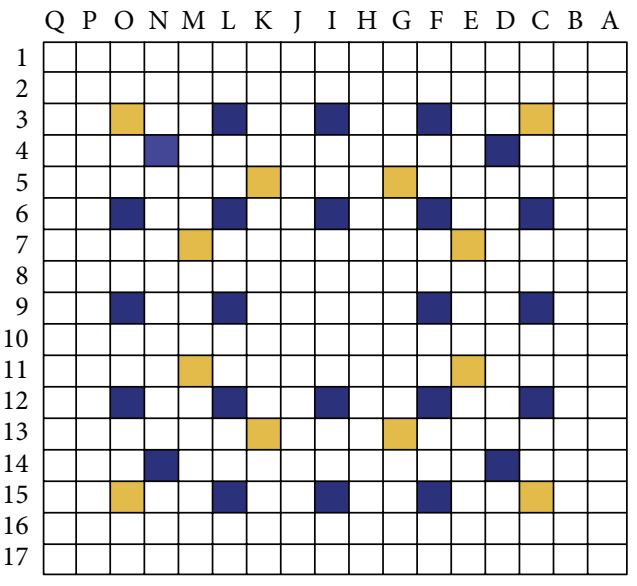

$\square$ Guide tube $\square \mathrm{UO}_{2} \mathrm{Gd}_{2} \mathrm{O}_{3} 2.2 \%{ }^{235} \mathrm{U}$ rod
$\square$ UOX 4.2\% ${ }^{235} \mathrm{U}$ rod

(d)

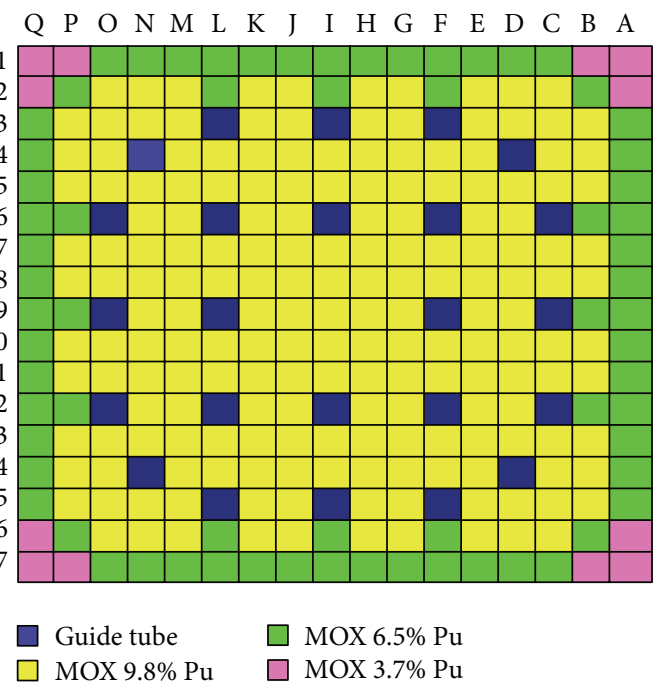

(f)

Figure 2: FAs for the test cases of Exercise I-2: BWR (a), PWR (b), GEN-III Type 1 (c), GEN-III Type 2 (d), GEN-III Type 3 (e), and GEN-III Type 4 (f). 


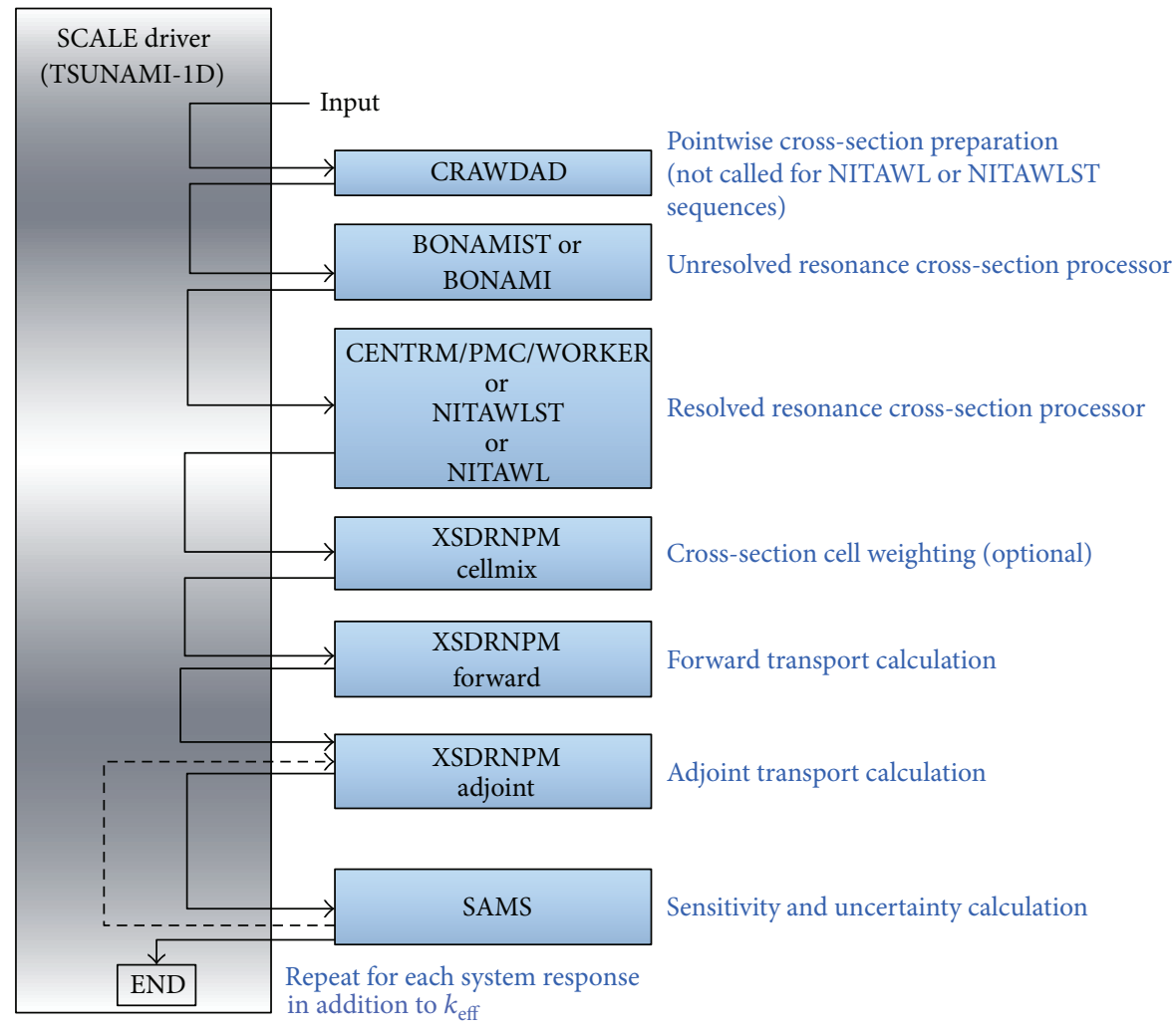

FIgURE 3: General flow diagram of the TSUNAMI code [7].

the flux is perturbed due to changes in $\mathrm{H}$ moderation. However there is also an implicit effect because changing the $\mathrm{H}$ data perturbs the self-shielded ${ }^{238} \mathrm{U}$ absorption cross section, which causes another flux perturbation.

Let us now consider a ratio response $R$ characterized by the macroscopic cross-sections $\Sigma_{1}$ and $\Sigma_{2}$ as follows:

$$
R=\frac{\left\langle\Sigma_{1} \Phi\right\rangle}{\left\langle\Sigma_{2} \Phi\right\rangle},
$$

where in (5) the brackets $\langle$,$\rangle indicate the integration over the$ phase space and $\Phi$ is the homogeneous flux. In this case the sensitivity coefficients are given by

$$
S_{j}^{R}=\left\langle\underline{\Psi}, \sigma_{j} \underline{\Phi}\right\rangle,
$$

where $\underline{\Psi}_{R}^{*}$ is the solution of

$$
M^{*} \underline{\Psi}_{R}^{*}=\frac{d R}{d \Phi}
$$

where $M^{*}$ is the adjoint Boltzmann operator. The uncertainties associated to the cross-section can be represented in the form of a variance-covariance matrix:

$$
D_{\sigma}=\left[\begin{array}{ccc}
d_{11} & \cdots & d_{1 J} \\
\vdots & \ddots & \vdots \\
d_{1 J} & \cdots & d_{J J}
\end{array}\right],
$$

where the elements $d_{i j}$ represent the variances and covariances of the nuclear data. Once the sensitivity coefficients and the $D_{\sigma}$ matrix are available, the variance (i.e., the uncertainty) of the generic integral parameter $Q$ can be expressed as

$$
\operatorname{var}(Q)=\sum_{j, i}^{J} S_{j} S_{i} d_{i j}
$$

All the calculations presented in this paper have been performed by means of the SCALE 6.1 code system [14] using ENDF/B-VII.0 nuclear data [15]. SCALE (Standardized Computer Analysis for Licensing Evaluations) is a modular code system developed at Oak Ridge National Laboratory to perform analysis for criticality safety, reactor physics and radiation shielding applications. SCALE calculations typically use sequences that execute a predefined series of executable modules to compute particle fluxes and responses (multiplication factor, reaction rates, etc.). SCALE also includes modules for sensitivity and uncertainty analysis $(\mathrm{S} / \mathrm{U})$ of calculated responses. The S/U codes in SCALE are collectively referred to as TSUNAMI (Tools for Sensitivity and Uncertainty Analysis Methodology Implementation) [7, 16]. The techniques used in TSUNAMI to generate sensitivity information are based on the widely used adjoint-based perturbation theory approach described above. The flow diagram of the TSUNAMI calculations is shown in Figure 3.

The calculation procedure for the multi-group crosssection processing is based on a rigorous mechanism using the continuous energy solvers BONAMI and CENTRM [17] for self-shielding in the unresolved and resolved resonance regions, respectively, for appropriately weighting multi-group 
cross-sections using a continuous energy spectrum. The CENTRM module performs transport calculation using ENDF-based point data on an ultrafine energy grid (typically 30.000-70.000 energy points) to generate effectively continuous energy neutron flux solutions in the resonance and thermal ranges. This is used to weight the multi-group crosssections to be utilized in the subsequent transport calculations. After the cross-sections are processed, the TSUNAMI1D sequence performs two criticality calculations, solving the forward and adjoint forms of the Boltzmann equation, respectively, using the XSDRNPM discrete ordinate code [18]. In this step an energy discretization based on a 238group structure is adopted. The sequence then calls the SAMS module, specifically SAMS5 [19], in order to compute the sensitivity coefficients. Once sensitivities are available, the uncertainty on the integral parameters of interest due to the uncertainty in the basic nuclear data are evaluated according to (9) using the so-called 44GROUPCOV covariance matrix [20]. The 44GROUPCOV matrix comprehends a total of 401 materials in a 44-group energy structure. The library includes evaluated covariances obtained from ENDF/B-VII, ENDF/BVI, and JENDL3.3 for more than 50 materials. It is assumed [20] that covariances taken from one data evaluation, such as ENDF/B-VI or JENDL-3.3, can also be applied to other evaluations of the same data, such as ENDF/B-VII. All other nuclear data uncertainties have been estimated from approximations in which the uncertainty assessment is decoupled from the original evaluation procedure.

\section{Results}

Results for the $k_{\text {eff }}$ values and associated uncertainties related to the benchmark test cases of Exercises I-1 and I-2 are summarized in Table 2. As expected, because of the negative fuel Doppler coefficient, the reactivities computed for all the test cases at HFP conditions are consistently lower than those at HZP conditions. The total uncertainties of the $k_{\text {eff }}$ have been evaluated to be $\sim 0.5 \%-0.6 \%$ for all the test cases with the exception of the GEN-III Type 4 case within Exercise I-2 where the computed uncertainty is higher by around a factor of two because of the presence of the plutonium isotopes in the fuel (MOX fuel). In Figure 4 the five reaction crosssections which contribute the most to the $k_{\text {eff }}$ uncertainty for the test cases of Exercise I-1 are shown. While for the UOX-fuelled test cases the main contribution to the total uncertainty is due to the ${ }^{238} \mathrm{U}(\mathrm{n}, \gamma)$ followed by the ${ }^{235} \mathrm{U}$ nubar (average number of neutrons per fission reaction $-v$ ) and ${ }^{235} \mathrm{U}(\mathrm{n}, \gamma)$; for the MOX-fuelled test case considered (GENIII) the predominant component to the total uncertainty comes from the ${ }^{239} \mathrm{Pu}$ nubar followed by the ${ }^{238} \mathrm{U}\left(\mathrm{n}, \mathrm{n}^{\prime}\right)$ and ${ }^{239} \mathrm{Pu}$ (n,fission). By definition the reason for these main contributions to the uncertainty can be due to the highest sensitivities associated to such reactions, to the highest value of the associated covariances, or to a combination of both. As an example, in the case of the ${ }^{238} \mathrm{U}(\mathrm{n}, \gamma)$, on one hand, the $k_{\text {eff }}$ is quite sensitive to its value (especially in the unresolved resonance regions), and on the other hand its evaluation is still quite "uncertain", and evaluated cross-sections from various
TABLE 2: Exercises I-1 and I-2 results: $k_{\text {eff }}$.

\begin{tabular}{|c|c|c|}
\hline Test cases & $k_{\text {eff }}$ & Uncertainty $(\% \Delta \mathrm{R} / \mathrm{R})$ \\
\hline \multicolumn{3}{|c|}{ Exercise I-1 } \\
\hline \multicolumn{3}{|l|}{ BWR } \\
\hline $\mathrm{HZP}$ & 1.34050 & $5.23 E-01$ \\
\hline HFP & 1.22270 & $6.16 E-01$ \\
\hline \multicolumn{3}{|l|}{ PWR } \\
\hline $\mathrm{HZP}$ & 1.42290 & $4.82 E-01$ \\
\hline HFP & 1.40424 & $4.89 E-01$ \\
\hline \multicolumn{3}{|l|}{ VVER } \\
\hline $\mathrm{HZP}$ & 1.34498 & $5.13 E-01$ \\
\hline HFP & 1.32725 & $5.20 E-01$ \\
\hline \multicolumn{3}{|l|}{ KRITZ-2:1 } \\
\hline Cold & 1.23394 & $5.87 E-01$ \\
\hline Hot & 1.18584 & $6.31 E-01$ \\
\hline \multicolumn{3}{|l|}{ GEN-III } \\
\hline HFP & 1.09591 & $5.20 E-01$ \\
\hline \multicolumn{3}{|c|}{ Exercise I-2 } \\
\hline \multicolumn{3}{|l|}{ PWR } \\
\hline $\mathrm{HZP}$ & 1.11029 & $5.00 E-01$ \\
\hline HFP & 1.07736 & $5.56 E-01$ \\
\hline \multicolumn{3}{|l|}{ BWR } \\
\hline $\mathrm{HZP}$ & 1.41009 & $4.64 E-01$ \\
\hline HFP & 1.39351 & $4.71 E-01$ \\
\hline GEN-III Type 1 & 1.25325 & $4.87 E-01$ \\
\hline GEN-III Type 2 & 1.12304 & $4.94 E-01$ \\
\hline GEN-III Type 3 & 1.04501 & $5.03 E-01$ \\
\hline GEN-III Type 4 & 1.07008 & $9.68 E-01$ \\
\hline
\end{tabular}

sources differ by more than their assigned uncertainties [21]. In Table 3 the explicit and implicit contributions to the total sensitivity coefficient of the ${ }^{238} \mathrm{U}$ absorption cross-sections are given. One can observe that for some oxygen and uranium isotopes cross-sections the implicit part computed by the TSUNAMI code is not negligible.

Also, the most relevant sensitivity profiles for the BWR PB-2 and GEN-III unit-cell cases are shown in Figures 5 and 6 , respectively. One of the benchmark requirements was the evaluation of the uncertainty associated to the calculation of the one-group absorption and fission microscopic crosssections for ${ }^{235} \mathrm{U}$ and ${ }^{238} \mathrm{U}$ within the test cases of Exercise I-1. The results are given in Table 4 . The uncertainty of the microscopic cross-section values is around one order of magnitude higher than the one of the $k_{\text {eff }}$ cases, ranging in between $\sim 1 \%$ and $\sim 4 \%$. The highest uncertainty value was systematically found for the fission cross-section of ${ }^{238} \mathrm{U}$. As far as the test cases of Exercise I-2 are concerned, as required from the benchmark specification, some selected homogenized macroscopic cross sections with the associated uncertainties have been evaluated in a two-group structure with a cutoff energy of $0.625 \mathrm{eV}$. Results are provided in Table 5. The first energy group $(E \leq 0.625 \mathrm{eV})$ was systematically found to be the one with the lower associated uncertainties. Also, as a general trend the uncertainties have been evaluated to 


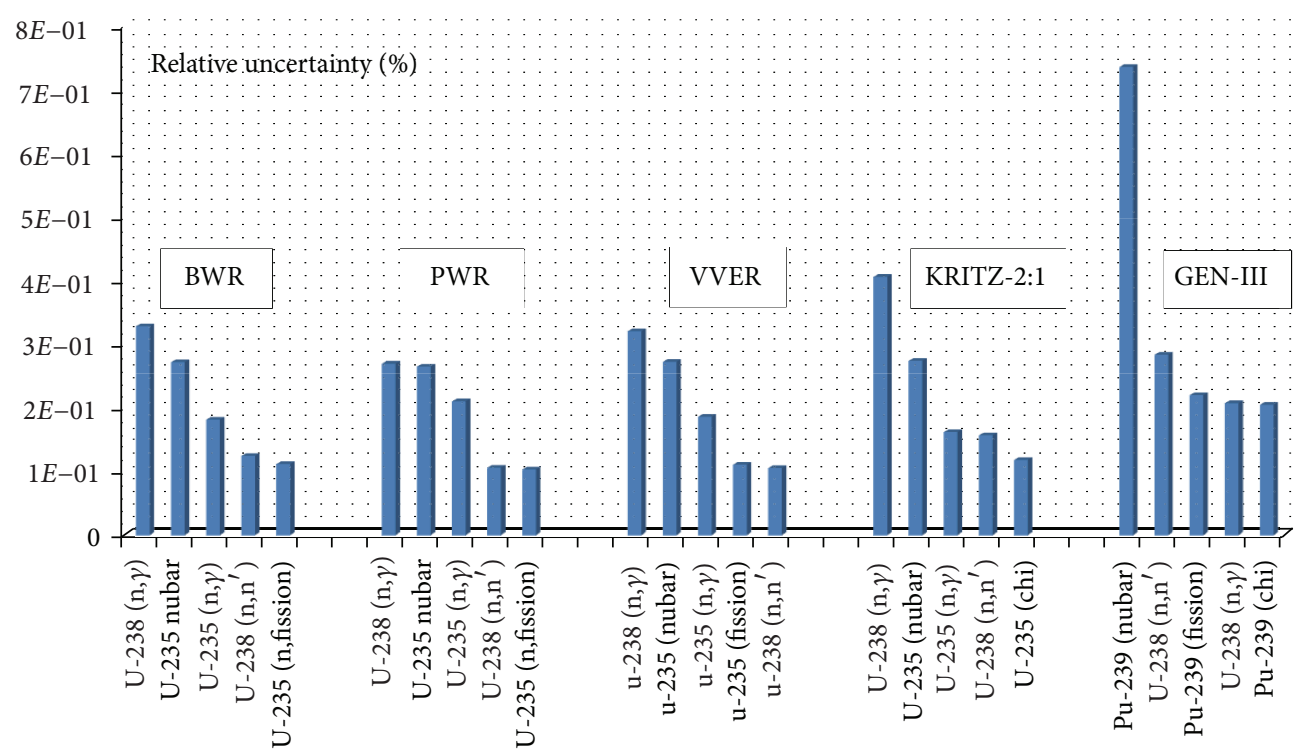

FIGURE 4: The five reaction cross-sections with the highest contribution to the $k_{\text {eff }}$ uncertainty for the test cases within Exercise I-1.
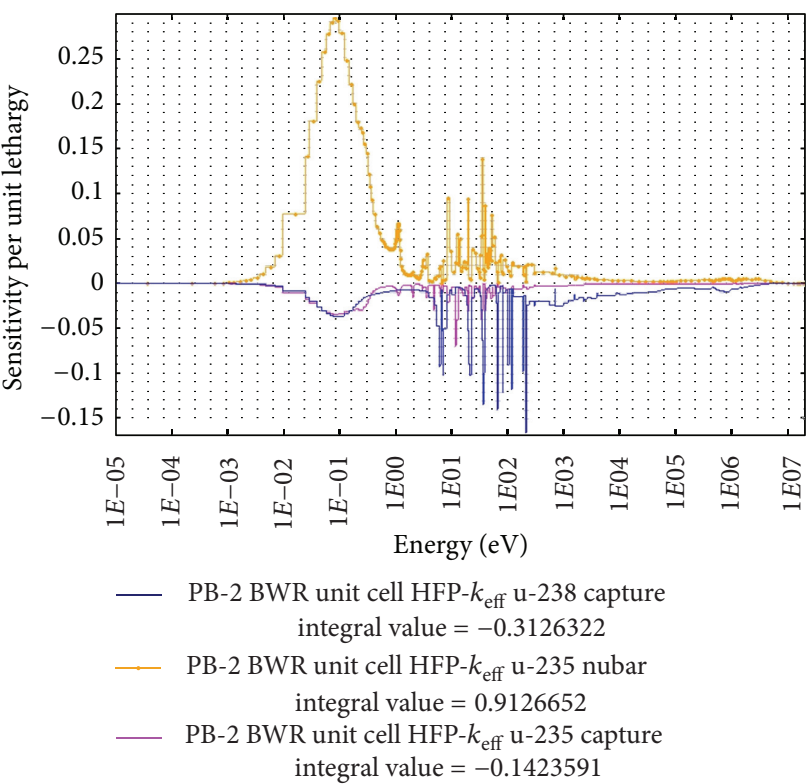

FIGURE 5: $k_{\text {eff }}$ sensitivity profiles for the BWR PB-2 unit cell case (HFP conditions).

be very consistent within all the test cases, and higher values (in the order of $1.35 \%$ ) were computed for the homogenized absorption cross-section.

\section{The Reference Solutions}

As part of the activities within the UAM benchmark. KIT and PSU are also working on the development of reference solutions for the test cases by means of Monte Carlo methodologies. As it is well known, the Monte Carlo method can be considered as a "numerical experiment" that represents a high quality reference solution for the validation of deterministic

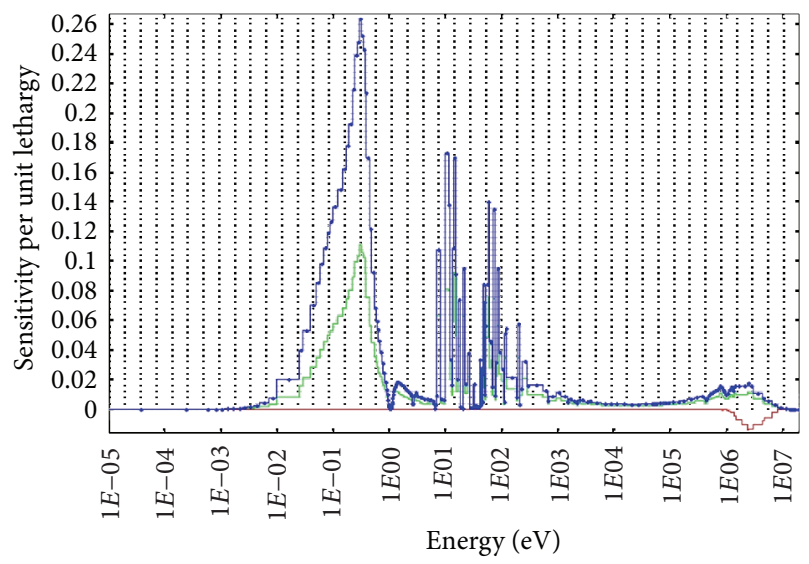

- MOX 9.8\% Pu unit cell HFP- $k_{\text {eff }}$ Pu-239 nubar integral value $=0.7276543$

- MOX 9.8\% Pu unit cell HFP- $k_{\text {eff }}$ Pu-235 n,n' integral value $=-0.01513715$

— MOX 9.8\% Pu unit cell HFP- $k_{\text {eff }} \mathrm{Pu}-239$ fission integral value $=0.3577213$

FIGURE 6: $k_{\text {eff }}$ sensitivity profiles for the GEN-III unit cell case (HFP conditions).

codes. For this purpose we are mainly using the SERPENT code [22], a Monte Carlo code designed for lattice physics calculations [23]. A comparison between absorption and fission microscopic cross sections values as computed with SERPENT and SCALE and relative to three test cases within Exercise I-1 is summarized in Table 6 . A very good agreement between the two approaches can be observed. $k_{\text {eff }}$ values computed by means of the SERPENT code (v. 1.1.16) with different sets of NDLs are summarized in Table 7. As far as the modeling, a good statistics in the criticality calculations has been achieved by simulating $5.0 E+6$ neutron histories 
TABLE 3: Exercise I-1: PWR test case at HFP: energy integrated sensitivity coefficients of the ${ }^{238} \mathrm{U}$ absorption cross-section with respect to different cross-section isotopes.

\begin{tabular}{|c|c|c|c|c|}
\hline Nuclide & Reaction & Explicit & Implicit & Sensitivity \\
\hline${ }^{16} \mathrm{O}$ & Total & $3.00 E-02$ & $1.19 E-02$ & $4.19 E-02$ \\
\hline${ }^{16} \mathrm{O}$ & Scattering & $2.99 E-02$ & $1.19 E-02$ & $4.18 E-02$ \\
\hline${ }^{16} \mathrm{O}$ & Elastic & $2.99 E-02$ & $1.19 E-02$ & $4.18 E-02$ \\
\hline${ }^{16} \mathrm{O}$ & $\mathrm{n}, \mathrm{n}^{\prime}$ & $1.37 E-05$ & $-1.95 E-08$ & $1.37 E-05$ \\
\hline${ }^{16} \mathrm{O}$ & $\mathrm{n}, 2 \mathrm{n}$ & $4.32 E-12$ & $-2.24 E-17$ & $4.32 E-12$ \\
\hline${ }^{16} \mathrm{O}$ & $\mathrm{n}, \gamma$ & $-8.21 E-07$ & $1.00 E-08$ & $-8.11 E-07$ \\
\hline${ }^{16} \mathrm{O}$ & $\mathrm{n}, \mathrm{p}$ & $-1.90 E-07$ & $-2.02 E-11$ & $-1.90 E-07$ \\
\hline${ }^{16} \mathrm{O}$ & $\mathrm{n}, \mathrm{d}$ & $-4.02 E-08$ & $-1.07 E-12$ & $-4.02 E-08$ \\
\hline${ }^{16} \mathrm{O}$ & $\mathrm{n}, \mathrm{t}$ & $-5.75 E-13$ & $-5.14 E-18$ & $-5.75 E-13$ \\
\hline${ }^{16} \mathrm{O}$ & n,alpha & $1.12 E-04$ & $2.69 E-08$ & $1.12 E-04$ \\
\hline${ }^{234} \mathrm{U}$ & Total & $-4.27 E-05$ & $2.05 E-06$ & $-4.07 E-05$ \\
\hline${ }^{234} \mathrm{U}$ & Scattering & $-9.13 E-08$ & $1.47 E-06$ & $1.37 E-06$ \\
\hline${ }^{234} \mathrm{U}$ & Elastic & $-9.43 E-07$ & $1.47 E-06$ & $5.23 E-07$ \\
\hline${ }^{234} \mathrm{U}$ & $\mathrm{n}, \mathrm{n}^{\prime}$ & $8.50 E-07$ & $3.27 E-10$ & $8.50 E-07$ \\
\hline${ }^{234} \mathrm{U}$ & $n, 2 n$ & $1.99 E-09$ & $-1.12 E-13$ & $1.99 E-09$ \\
\hline${ }^{234} \mathrm{U}$ & Fission & $4.15 E-08$ & $4.34 E-09$ & $4.58 E-08$ \\
\hline${ }^{234} \mathrm{U}$ & $\mathrm{n}, \gamma$ & $-4.27 E-05$ & $5.83 E-07$ & $-4.21 E-05$ \\
\hline${ }^{234} \mathrm{U}$ & Nubar & $4.36 E-08$ & - & $4.36 E-08$ \\
\hline${ }^{234} \mathrm{U}$ & Chi & $-3.13 E-15$ & - & $-3.13 E-15$ \\
\hline${ }^{235} \mathrm{U}$ & Total & $-1.01 E-01$ & $3.36 E-03$ & $-9.75 E-02$ \\
\hline${ }^{235} \mathrm{U}$ & Scattering & $1.08 E-03$ & $8.97 E-04$ & $1.97 E-03$ \\
\hline${ }^{235} \mathrm{U}$ & Elastic & $-9.45 E-05$ & $8.96 E-04$ & $8.01 E-04$ \\
\hline${ }^{235} \mathrm{U}$ & $\mathrm{n}, \mathrm{n}^{\prime}$ & $1.16 E-03$ & $8.01 E-07$ & $1.16 E-03$ \\
\hline${ }^{235} \mathrm{U}$ & $\mathrm{n}, 2 \mathrm{n}$ & $1.38 E-05$ & $-1.14 E-09$ & $1.38 E-05$ \\
\hline${ }^{235} \mathrm{U}$ & Fission & $-7.56 E-02$ & $1.39 E-03$ & $-7.42 E-02$ \\
\hline${ }^{235} \mathrm{U}$ & $\mathrm{n}, \gamma$ & $-2.63 E-02$ & $1.07 E-03$ & $-2.53 E-02$ \\
\hline${ }^{235} \mathrm{U}$ & Nubar & $-2.75 E-04$ & - & $-2.75 E-04$ \\
\hline${ }^{235} \mathrm{U}$ & Chi & $1.22 E-11$ & - & $1.22 E-11$ \\
\hline${ }^{238} \mathrm{U}$ & Total & $7.85 E-01$ & $-8.43 E-02$ & $7.01 E-01$ \\
\hline${ }^{238} \mathrm{U}$ & Scattering & $3.25 E-02$ & $-5.69 E-02$ & $-2.44 E-02$ \\
\hline${ }^{238} \mathrm{U}$ & Elastic & $4.68 E-03$ & $-5.69 E-02$ & $-5.22 E-02$ \\
\hline${ }^{238} \mathrm{U}$ & $\mathrm{n}, \mathrm{n}^{\prime}$ & $2.75 E-02$ & $8.91 E-06$ & $2.75 E-02$ \\
\hline${ }^{238} \mathrm{U}$ & $n, 2 n$ & $3.38 E-04$ & $8.26 E-08$ & $3.38 E-04$ \\
\hline${ }^{238} \mathrm{U}$ & Fission & $1.04 E-01$ & $-3.16 E-07$ & $1.04 E-01$ \\
\hline${ }^{238} \mathrm{U}$ & $\mathrm{n}, \gamma$ & $6.48 E-01$ & $-2.74 E-02$ & $6.21 E-01$ \\
\hline${ }^{238} \mathrm{U}$ & Nubar & $1.38 E-04$ & - & $1.38 E-04$ \\
\hline${ }^{238} \mathrm{U}$ & Chi & $-1.12 E-12$ & - & $-1.12 E-12$ \\
\hline
\end{tabular}

over 1000 active cycles (5000 neutron source $\times 1000$ cycles). Continuous cross-section libraries in SERPENT are given in steps of $300 \mathrm{~K}(300 \mathrm{~K}, 600 \mathrm{~K}$, etc.), and the "actual" problem temperatures have been simulated by defining a mix of two materials with proportions equal to the weighted averages in between the two closest temperatures sets as available in SERPENT package. One can observe quite a good agreement in between the results with the different NDLs. Also, a systematic slight increase in the prediction of the $k_{\text {eff }}$ when switching from JEFF3.1 to JEFF3.1.1 up to ENDF/BVII, respectively, can be noted. $k_{\text {eff }}$ computed with JEFF3.1.1 are larger by $\sim 100 \mathrm{pcm}$ with respect to those obtained from JEFF3.1, and this is mainly due to the improvement of the ${ }^{16} \mathrm{O}(\mathrm{n}, \alpha)$ cross section which was decreased by $30 \%$ in the JEFF3.1.1 evaluation [24]. The comparison of these values with the correspondent ones obtained from the SCALE6.1 code (see Table 2) shows some discrepancies. One of the reasons for these differences was found to be due to the different Boundary Conditions (BCs) used in the SERPENT modeling; the "white" BC is not yet implemented in SERPENT, and therefore the "reflective" BC has been adopted for our simulations. In order to assess the impact of the 
TABLE 4: Exercises I-1: one-group microscopic cross-sections.

\begin{tabular}{|c|c|c|c|c|}
\hline \multirow{3}{*}{$\begin{array}{l}\text { Exercise I-1 } \\
\text { test cases }\end{array}$} & \multicolumn{4}{|c|}{ Microscopic cross-section (barn) } \\
\hline & ${ }^{235} \mathrm{U}$ absorption & ${ }^{238} \mathrm{U}$ absorption & ${ }^{235} \mathrm{U}$ fission & ${ }^{238} \mathrm{U}$ fission \\
\hline & (uncertainty \%) & (uncertainty \%) & (uncertainty \%) & (uncertainty \%) \\
\hline \multicolumn{5}{|l|}{ BWR } \\
\hline HZP & $2.01 E+01(1.04 E+00)$ & $3.10 E-01(9.80 E-01)$ & $1.65 E+01(1.06 E+00)$ & $3.01 E-02(4.07 E+00)$ \\
\hline HFP & $4.15 E+01(1.22 E+00)$ & $8.80 E-01(9.70 E-01)$ & $3.34 E+01(1.22 E+00)$ & $8.57 E-02(4.79 E+00)$ \\
\hline \multicolumn{5}{|l|}{ PWR } \\
\hline HZP & $4.41 E+01(1.09 E+00)$ & $9.42 E-01(9.65 E-01)$ & $3.57 E+01(1.10 E+00)$ & $9.91 E-02(3.92 E+00)$ \\
\hline HFP & $4.30 E-01(1.10 E+00)$ & $9.64 E-01(9.71 E-01)$ & $3.47 E+01(1.11 E+00)$ & $9.91 E-02(3.94 E+00)$ \\
\hline \multicolumn{5}{|l|}{ VVER } \\
\hline HZP & $5.98 E+01(1.02 E+00)$ & $1.02 E+00(9.88 E+01)$ & $4.90 E+01(1.04 E+00)$ & $9.26 E-02(3.86 E+00)$ \\
\hline HFP & $5.84 E+01(1.03 E+00)$ & $1.04 E+00(9.90 E-01)$ & $4.78 E+01(1.05 E+00)$ & $9.27 E-02(3.88 E+00)$ \\
\hline \multicolumn{5}{|l|}{ KRITZ-2: 1} \\
\hline Cold & $8.23 E+01(1.07 E+00)$ & $1.01 E+00(1.02 E+00)$ & $6.83 E+01(1.09 E+00)$ & $8.90 E-02(4.20 E+00)$ \\
\hline Hot & $2.71 E+01(1.13 E+00)$ & $3.84 E-01(1.01 E+00)$ & $2.24 E-01(1.15 E+00)$ & $3.38 E-02(4.51 E+00)$ \\
\hline \multicolumn{5}{|l|}{ GEN-III } \\
\hline HFP & $1.53 E+01 \quad(1.38 E+00)$ & $9.18 E-01(1.01 E+00)$ & $1.10 E+01(1.22 E+00)$ & $1.17 E-01(3.83 E+00)$ \\
\hline
\end{tabular}

TABLE 5: Exercise I-2 results: macroscopic cross-sections.

\begin{tabular}{|c|c|c|c|c|c|c|c|}
\hline \multirow{2}{*}{ Cross-section } & \multirow{2}{*}{ Energy group } & \multicolumn{6}{|c|}{ Value $\left(\mathrm{cm}^{-1}\right)$ (Uncertainty \%) } \\
\hline & & PWR & BWR & GEN-III Type 1 & GEN-III Type 2 & GEN-III Type 3 & GEN-III Type 4 \\
\hline \multirow{4}{*}{ Total } & \multirow{2}{*}{1} & $1.44 E+00$ & $1.58 E+00$ & $1.31 E+00$ & $1.32 E+00$ & $1.33 E+00$ & $1.50 E+00$ \\
\hline & & $(1.38 E-01)$ & $(1.29 E-01)$ & $(1.41 E-01)$ & $(1.39 E-01)$ & $(1.39 E-01)$ & $(1.39 E-01)$ \\
\hline & \multirow{2}{*}{2} & $5.69 E-01$ & $5.79 E-01$ & $5.33 E-01$ & $5.34 E-01$ & $5.34 E-01$ & $5.24 E-01$ \\
\hline & & $(8.78 E-01)$ & $(8.40 E-01)$ & $(9.04 E-01)$ & $(9.03 E-01)$ & $(9.01 E-01)$ & $(9.73 E-01)$ \\
\hline \multirow{4}{*}{ Absorption } & \multirow{2}{*}{1} & $1.11 E-01$ & $5.72 E-02$ & $1.07 E-01$ & $1.17 E-01$ & $3.45 E-1$ & $1.24 E-01$ \\
\hline & & $(8.77 E-01)$ & $(6.06 E-01)$ & $(7.00 E-01)$ & $(5.61 E-01)$ & $(9.79 E-01)$ & $(5.11 E-01)$ \\
\hline & \multirow{2}{*}{2} & $1.06 E-02$ & $7.32 E-03$ & $1.04 E-02$ & $1.06 E-02$ & $5.09 E-01$ & $1.07 E-02$ \\
\hline & & $(1.33 E+00)$ & $(1.38 E+00)$ & $(1.35 E+00)$ & $(1.34 E+00)$ & $(1.47 E+00)$ & $(1.34 E+00)$ \\
\hline \multirow{4}{*}{ Fission } & \multirow{2}{*}{1} & $7.95 E-01$ & $2.94 E-02$ & $6.86 E-02$ & $6.60 E-02$ & $1.90 E-01$ & $6.42 E-02$ \\
\hline & & $(3.17 E-03)$ & $(3.23 E-01)$ & $(3.23 E-01)$ & $(3.24 E-01)$ & $(6.26 E-01)$ & $(3.24 E-01)$ \\
\hline & \multirow{2}{*}{2} & $3.59 E-03$ & $1.95 E-03$ & $3.17 E-03$ & $3.10 E-03$ & $4.97 E-01$ & $3.05 E-03$ \\
\hline & & $(3.55 E-01)$ & $(6.81 E-01)$ & $(3.71 E-01)$ & $(3.75 E-01)$ & $(4.45 E-01)$ & $(3.80 E-01)$ \\
\hline \multirow{4}{*}{ Nufission } & \multirow{2}{*}{1} & $1.94 E-01$ & $7.02 E-02$ & $1.67 E-1$ & $1.61 E-01$ & $5.45 E-01$ & $1.56 E-01$ \\
\hline & & $(4.44 E-01)$ & $(4.49 E-01)$ & $(4.48 E-01)$ & $(4.49 E-01)$ & $(1.09 E+00)$ & $(4.49 E-01)$ \\
\hline & \multirow{2}{*}{2} & $9.08 E-03$ & $4.69 E-03$ & $8.02 E-03$ & $7.86 E-03$ & $1.44 E-02$ & $7.73 E-3$ \\
\hline & & $(5.12 E-01)$ & $(1.01 E+00)$ & $(5.71 E-01)$ & $(5.82 E-01)$ & $(7.75 E-01)$ & $(5.92 E-01)$ \\
\hline
\end{tabular}

different $\mathrm{BCs}$ on the computed reactivities, three test cases at HZP conditions have been modeled with the MCNP5 code (v. 1.40) [25] with "white" BCs. The corresponding results, which are given in Table 7 and have been obtained by simulating 1500 generation of 2000 neutrons each, show how the discrepancies are then reduced.

\section{Conclusions}

The neutronics modeling of some selected test cases within the "Neutronics Phase" of the OECD UAM Benchmark has been presented. A S/U analysis on the impact of the uncertainty in the basic nuclear data on the calculation of the multiplication factor and microscopic and macroscopic cross-sections have been performed using the perturbation methodologies implemented in the TSUNAMI code. Uncertainties were found to be $\sim 0.5 \%$ on $k_{\text {eff }}$ and higher (up to $\sim 4 \%$ ) for the cross-sections. The ${ }^{238} \mathrm{U}$ capture crosssection and the ${ }^{239} \mathrm{Pu}$ nubar were found to be the highest contributors to the total uncertainty for the UOX and MOX LWR's representative test cases. The deterministic solutions were also compared with the corresponding reference solutions obtained using Monte Carlo methods, and a good 
TABLE 6: Phase I-1 Exercises.

\begin{tabular}{lccc}
\hline Micro-XS & SCALE 6.1 & SERPENT & $\begin{array}{c}\text { Uncertainty due to } \\
\text { nuclear data (\%) }\end{array}$ \\
\hline${ }^{235} \mathrm{U}$ absorption & 41.48 & $40.41 \pm 0.0086$ & 1.22 \\
${ }^{238} \mathrm{U}$ absorption & 0.88 & $0.80 \pm 0.0011$ & 0.97 \\
${ }^{235} \mathrm{U}$ fission & 33.43 & $32.56 \pm 0.00069$ & 1.22 \\
${ }^{238} \mathrm{U}$ fission & 0.086 & $0.089 \pm 0.00097$ & 4.79 \\
${ }^{235} \mathrm{U}$ absorption & 42.95 & $42.18 \pm 0.00088$ & 1.09 \\
${ }^{238} \mathrm{U}$ absorption & 0.96 & $0.93 \pm 0.0011$ & 0.97 \\
${ }^{235} \mathrm{U}$ fission & 34.72 & $34.10 \pm 0.00064$ & 1.11 \\
${ }^{238} \mathrm{U}$ fission & 0.099 & $0.10 \pm 0.00096$ & 3.94 \\
${ }^{235} \mathrm{U}$ absorption & 58.13 & $57.26 \pm 0.00085$ & 1.03 \\
${ }^{238} \mathrm{U}$ absorption & 1.042 & $1.005 \pm 0.0012$ & 0.99 \\
${ }^{235} \mathrm{U}$ fission & 47.84 & $47.76 \pm 0.00063$ & 1.05 \\
${ }^{238} \mathrm{U}$ fission & 0.093 & $0.095 \pm 0.00100$ & 3.88 \\
\hline
\end{tabular}

TABLE 7: Phase I-1 Exercise: $k_{\text {eff }}$ evaluation with SERPENT and MCNP*.

\begin{tabular}{|c|c|c|c|}
\hline \multirow{2}{*}{ Test case } & \multicolumn{3}{|c|}{$k_{\text {eff }}$} \\
\hline & JEFF3.1 & JEFF 3.1.1 & ENDFB-7 \\
\hline \multicolumn{4}{|l|}{ VVER } \\
\hline HZP & $1.34764 \pm 0.00028$ & $1.34937 \pm 0.00026$ & $\begin{array}{c}1.34986 \pm 0.00027 \\
1.34542 \pm 0.00029^{*}\end{array}$ \\
\hline HFP & $1.33152 \pm 0.00028$ & $1.33356 \pm 0.00029$ & $1.33435 \pm 0.00029$ \\
\hline \multicolumn{4}{|l|}{ PWR } \\
\hline $\mathrm{HZP}$ & $1.42785 \pm 0.00027$ & $1.42888 \pm 0.00025$ & $\begin{array}{c}1.42923 \pm 0.00027 \\
1.42018 \pm 0.00030^{*}\end{array}$ \\
\hline HFP & $1.41136 \pm 0.00026$ & $1.41315 \pm 0.00028$ & $1.41401 \pm 0.00026$ \\
\hline \multicolumn{4}{|l|}{ BWR } \\
\hline HZP & $1.34541 \pm 0.00027$ & $1.34673 \pm 0.00025$ & $\begin{array}{c}1.34691 \pm 0.00026 \\
1.34191 \pm 0.00034^{*}\end{array}$ \\
\hline HFP & $1.23046 \pm 0.00032$ & $1.23080 \pm 0.00032$ & $1.23295 \pm 0.00032$ \\
\hline \multicolumn{4}{|c|}{ KRITZ-2: 1} \\
\hline Cold & $1.23762 \pm 0.00028$ & $1.23846 \pm 0.00027$ & $1.23984 \pm 0.00027$ \\
\hline Hot & $1.22632 \pm 0.00028$ & $1.22864 \pm 0.00026$ & $1.22863 \pm 0.00027$ \\
\hline \multicolumn{4}{|l|}{ GEN-III } \\
\hline HFP & $1.01485 \pm 0.00039$ & $1.01602 \pm 0.00039$ & $1.01805 \pm 0.00037$ \\
\hline
\end{tabular}

agreement has been found for several cases, particularly in the evaluation of the microscopic cross-sections.

\section{References}

[1] K. Ivanov et al., "Benchmark for Uncertainy Analysis in Modeling (UAM) for Design, Operation and Safety Analysis of LWRs," NEA/NSC/DOC, 2012.

[2] J. Solis, K. Ivanov, B. Sarikaya, A. Olson, and K. Hunt, "BWR TT Benchmark. Volume I: Final Specifications," NEA/NSC/DOC, 2001.

[3] K. Ivanov, T. Beam, A. Baratta, A. Irani, and N. Trikouros, "PWR MSLB Benchmark. Volume 1: Final Specifications," NEA/NSC/DOC(99), 1999.

[4] B. Ivanov, K. Ivanov, P. Groudev, M. Pavlova, and V. Hadjiev, "VVER-1000 Coolant Transient Benchmark (V1000-CT). Phase 1-Final Specification," NEA/NSC/DOC, 2002.
[5] "Benchmark on the KRITZ-2 LEU and MOX Critical Experiments-Final Report," NEA/NSC/DOC, 2005.

[6] C. Vaglio and A. Santamarina, "Assembly and core specification of generation 3 PWR," CEA Report, 2010.

[7] B. Rearden, C. M. Hopper, K. R. Elam et al., "Applications of the TSUNAMI sensitivity and uncertainty analysis methodology," in Proceedings of the 7th International Conference on Nuclear Criticality Safety (ICNC '03), Tokai-mura, Japan, October 2003.

[8] G. Palmiotti and M. Salvatores, "Developments in sensitivity methodologies and the validation of reactor physics calculations," Science and Technology of Nuclear Installations, vol. 2012, Article ID 529623, 14 pages, 2012.

[9] H. Brooks, "Perturbation Theory for Boltzmann Equation," KAPL-304, 1950.

[10] G. Aliberti, L. Mercatali, G. Palmiotti, and M. Salvatores, "A systematic approach to nuclear data uncertainties and their 
impact on transmutation strategies," in Proceedings of the International Workshops on Nuclear Data for Transmutation, Darmstadt, Germany, September 2003.

[11] A. Gandini, "Uncertainty analysis and experimental data transposition methods based on perturbation theory," in Uncertainty Analysis, Y. Ronen, Ed., CRC Press, Boca Raton, Fla, USA, 1988.

[12] E. Greenspan, "Developments in perturbation theory," in Advances in Nuclear Science and Technology, J. Lewins and A. Becker, Eds., vol. 14, Plenum Press, 1982.

[13] M. L. Williams, B. L. Broadhead, and C. V. Parks, "Eigenvalue sensitivity theory for resonance-shielded cross sections," Nuclear Science and Engineering, vol. 138, no. 2, pp. 177-191, 2001.

[14] "SCALE: A Comprehensive Modeling and Simulation Suite for Nuclear Safety Analysis and Design," ORNL/TM-2005/39, Version 6.1. Oak Ridge National Laboratory. Radiation Safety Information Computational Center at Oak Ridge National Laboratory as CCC-785, 2011.

[15] M. B. Chadwick, P. Obložinský, M. Herman et al., "ENDF/BVII.0: next generation evaluated nuclear data library for nuclear science and technology," Nuclear Data Sheets, vol. 107, pp. 29313060, 2006.

[16] B. T. Rearden, M. L. Williams, M. A. Jessee, D. E. Mueller, and D. A. Wiarda, "Sensitivity and uncertainty analysis capabilities and data in SCALE," Nuclear Technology, vol. 174, no. 2, pp. 236-288, 2011.

[17] M. L. Williams, "Resonance self-shielding methodologies," Nuclear Technology, vol. 174, pp. 149-168, 2011.

[18] N. M. Greene, L. M. Petrie, and M. L. Williams, "XSDRNPM: A One-Dimensional Discrete-Ordinates Code for Transport Analysis," ORNL/TM-2005/39, 2011.

[19] B. T. Rearden, L. M. Petrie, M. A. Jessee, and M. L. Williams, "SAMS: Sensitivity Analysis Module for SCALE," ORNL/TM2005/39, 2011.

[20] M. L. Williams, D. Wiarda, G. Arbanas, and B. L. Broadhead, "SCALE Nuclear Data Covariance library," ORNL/TM-2005/39, 2011.

[21] A. Trkov, G. L. Molnár, Z. Révay et al., "Revisiting the ${ }^{238} \mathrm{U}$ thermal capture cross section and gamma-ray emission probabilities from ${ }^{239} \mathrm{~Np}$ decay," Nuclear Science and Engineering, vol. 150, no. 3, pp. 336-348, 2005.

[22] J. Leppänen, Development of a new Monte Carlo reactor physics code [D. Sc. Thesis], Helsinki University of Technology, 2007.

[23] E. Fridman and J. Leppänen, "On the use of the Serpent Monte Carlo code for few-group cross section generation," Annals of Nuclear Energy, vol. 38, no. 6, pp. 1399-1405, 2011.

[24] “The JEFF-3.1.1 Nuclear Data Library," NEA JEFF Report 22, OECD, 2009.

[25] X-5 Monte Carlo Team, "MCNP-A General Monte Carlo NParticle Transport Code (Version 5)," Los Alamos National Laboratory. LA-CP-03-0245, 2003. 


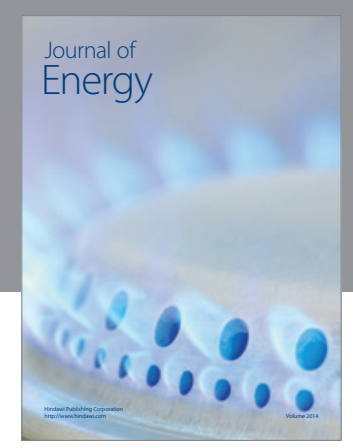

Journal of

Industrial Engineering
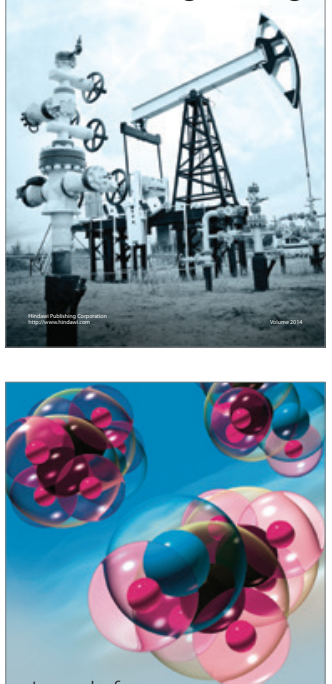

Fuels
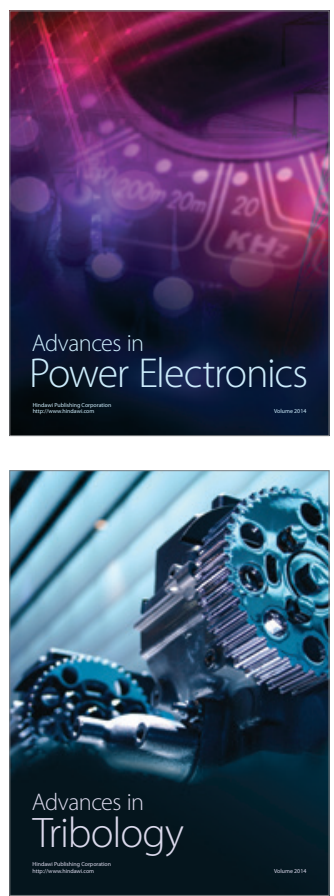

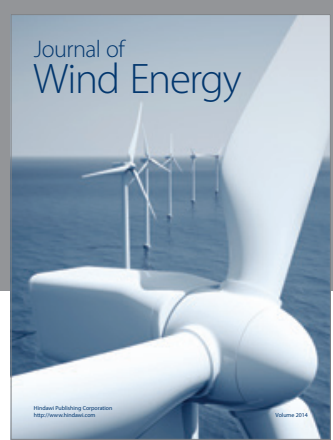

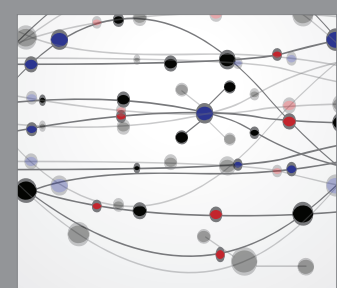

The Scientific World Journal

Submit your manuscripts at http://www.hindawi.com

Journal of

Structures
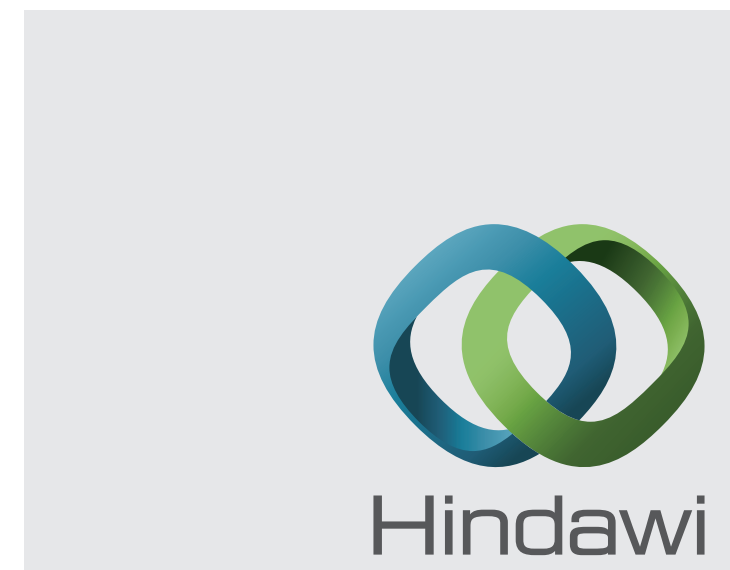

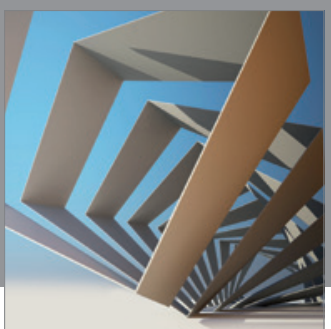

Rotating

Machinery
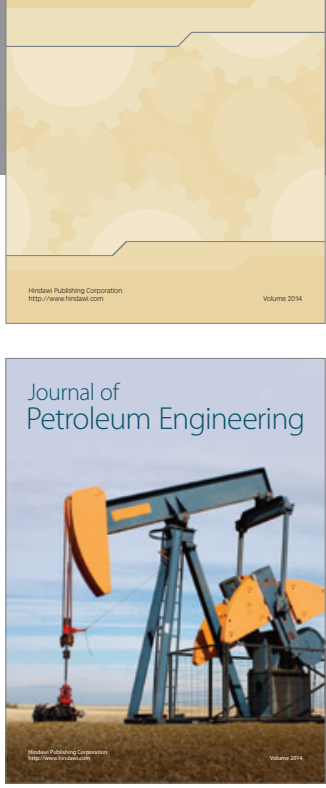

Journal of

Solar Energy
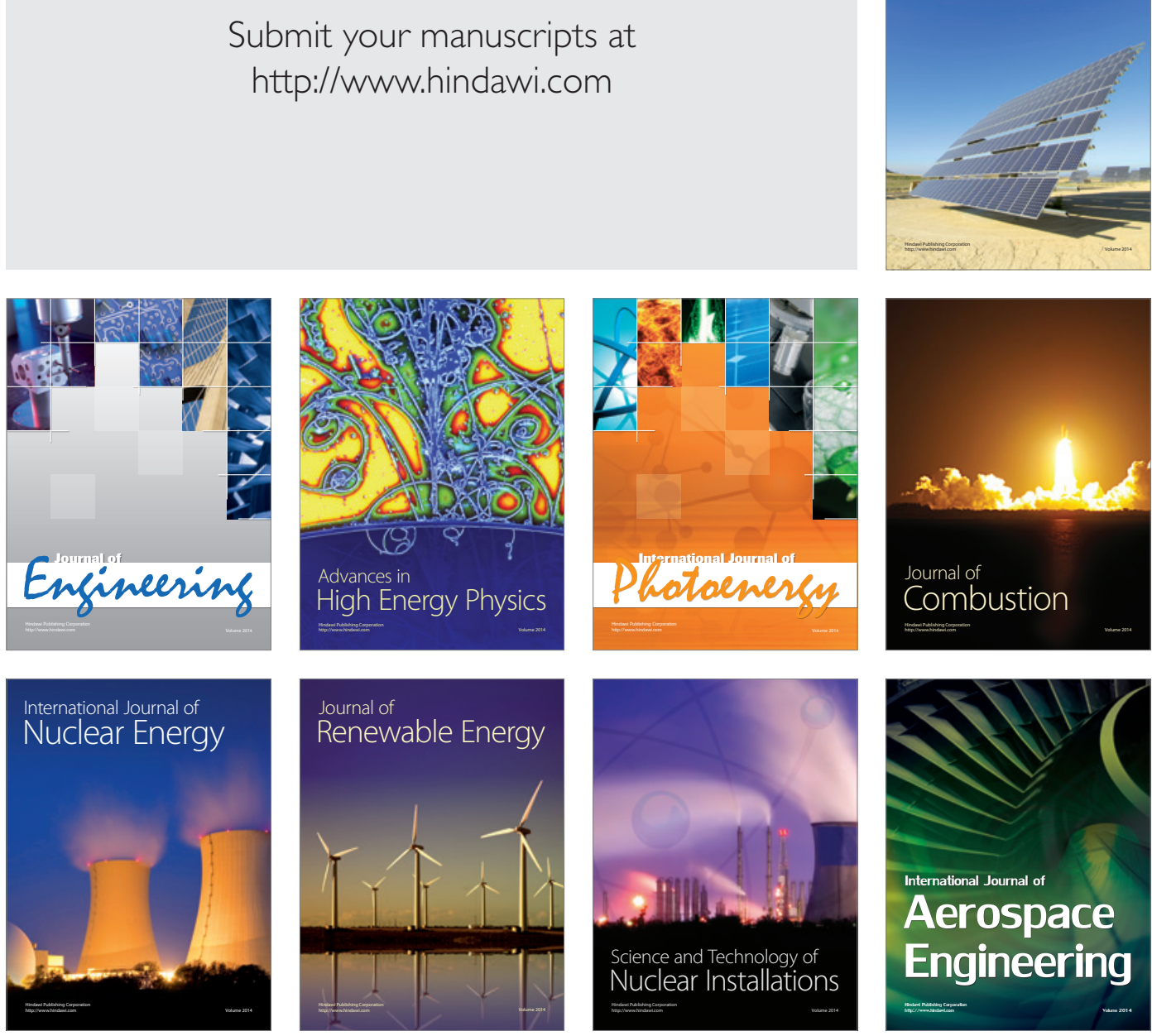